\title{
Pollution Characteristics, Distribution and Ecological Risk of Potentially Toxic Elements in Soils from an Abandoned Coal Mine Area in Southwestern China
}

\author{
Libo Pan ${ }^{1}$, Xiao Guan ${ }^{1, *}$, Bo Liu ${ }^{1}$, Yanjun Chen ${ }^{1}$, Ying Pei ${ }^{1}$, Jun Pan ${ }^{2}$, Yi Zhang ${ }^{2}$ and Zhenzhen Hao ${ }^{1}$ \\ 1 Ecological Department, Chinese Research Academy of Environmental Sciences, Beijing 100012, China; \\ panlb@craes.org.cn (L.P.); liubo@craes.org.cn (B.L.); chenyj@craes.org.cn (Y.C.); peiying@craes.org.cn (Y.P.); \\ haozhenzhen2021@126.com (Z.H.) \\ 2 Water Department, Guiyang Bureau of Ecology and Environment, Guiyang 550000, China; \\ panjun2021@126.com (J.P.); sthjjshjc@guiyang.gov.cn (Y.Z.) \\ * Correspondence: guanxiao@craes.org.cn
}

check for updates

Citation: Pan, L.; Guan, X.; Liu, B.; Chen, Y.; Pei, Y.; Pan, J.; Zhang, Y.; Hao, Z. Pollution Characteristics, Distribution and Ecological Risk of Potentially Toxic Elements in Soils from an Abandoned Coal Mine Area in Southwestern China. Minerals 2021, 11, 330. https://doi.org/10.3390/ $\min 11030330$

Academic Editors: Ana Romero-Freire and Hao Qiu

Received: 29 January 2021

Accepted: 16 March 2021

Published: 22 March 2021

Publisher's Note: MDPI stays neutral with regard to jurisdictional claims in published maps and institutional affiliations.

Copyright: (c) 2021 by the authors. Licensee MDPI, Basel, Switzerland. This article is an open access article distributed under the terms and conditions of the Creative Commons Attribution (CC BY) license (https:// creativecommons.org/licenses/by/ $4.0 /)$.

\begin{abstract}
Acid mine drainage (AMD) from abandoned coal mines can lead to serious environmental problems due to its low $\mathrm{pH}$ and high concentrations of potentially toxic elements. In this study, soil $\mathrm{pH}$, sulfur (S) content, and arsenic (As), cadmium (Cd), chromium $(\mathrm{Cr})$, copper $(\mathrm{Cu})$, lead $(\mathrm{Pb})$, nickel (Ni), zinc $(\mathrm{Zn})$, iron $(\mathrm{Fe})$, manganese $(\mathrm{Mn})$, and mercury $(\mathrm{Hg})$ concentrations were measured in 27 surface soil samples from areas in which coal-mining activities ceased nine years previously in Youyu Catchment, Guizhou Province, China. The soil was acidic, with a mean $\mathrm{pH}$ of 5.28. Cadmium was the only element with a mean concentration higher than the national soil quality standard. As, Cd, $\mathrm{Cu}, \mathrm{Ni}, \mathrm{Zn}, \mathrm{Mn}, \mathrm{Cr}$, and Fe concentrations were all higher than the background values in Guizhou Province. This was especially true for the $\mathrm{Cd}, \mathrm{Cu}$, and Fe concentrations, which were 1.69, 1.95, and 12.18 times their respective background values. The geoaccumulation index of $\mathrm{Cd}$ and Fe was present at unpolluted to moderately polluted and heavily polluted levels, respectively, indicating higher pollution levels than for the other elements in the study area. Spatially, significantly high Fe and $\mathrm{S}$ concentrations, as well as extremely low $\mathrm{pH}$ values, were found in the soils of the AMD sites; however, sites where tributaries merged with the Youyu River (TM) had the highest Cd pollution level. Iron originated mainly from non-point sources (e.g., AMD and coal gangues), while AMD and agricultural activity were the predominant sources of $\mathrm{Cd}$. The results of an eco-risk assessment indicated that $\mathrm{Cd}$ levels presented a moderate potential ecological risk, while the other elements all posed a low risk. For the TM sites, the highest eco-risk was for $\mathrm{Cd}$, with levels that could be harmful for aquatic organisms in the wet season, and may endanger human health via the food chain.
\end{abstract}

Keywords: acid mine drainage; abandoned coal mine; potentially toxic elements; pollution level; potential ecological risk

\section{Introduction}

Mining activity has important economic and social benefits; however, inadequately treated acid mine drainage (AMD) is globally recognized as one of the environmental issues, due to its acidic nature (extremely low $\mathrm{pH}$ of $<3$ ), and the presence of different potentially toxic elements, such as cadmium $(\mathrm{Cd})$, copper $(\mathrm{Cu})$, iron $(\mathrm{Fe})$, manganese $(\mathrm{Mn})$, lead $(\mathrm{Pb})$, and zinc ( $\mathrm{Zn})$, toxic metalloids (e.g., arsenic (As) and selenium (Se), and sulfates) [1,2], posed high threat to soil, water, and the local inhabitants in the mine-affected areas. Acid mine drainage (AMD) occurs in sulfide-bearing mine waste due to the oxidation of iron sulfides, especially pyrite $\left(\mathrm{FeS}_{2}\right)$, pyrrhotite $(\mathrm{FeS})$ and marcasite $\left(\mathrm{FeS}_{2}\right)$ leading to the creation of several soluble hydrous iron sulfates, the generation of acidity and subsequent leaching of metals [3-6]. Acid mine drainage can lead to soil acidification, which reduces soil enzyme activity, and inhibits plant respiration. Simultaneously, the low $\mathrm{pH}$ promotes 
the growth of acidophilic microorganisms, further accelerating the generation of AMD [7]. However, the potentially toxic elements in AMD can be ingested by plants, animals, and humans through the food chain, where their enrichment can harm human health [8]. Another prominent feature of AMD is its high Fe concentration, which is of great concern because it can influence the biogeochemistry of the ambient environment [9]. A diverse range of microorganisms capable of metabolizing Fe compounds can be leached from AMD into soils, and may play an important role in Fe cycling in soils. Therefore, the Fe cycle can potentially lead to unique microbial community assemblages in AMD-impacted soils compared to pristine soils [10].

Guizhou is located in southwestern China and has some of the country's largest coal resources. The coal reserves of Guizhou, which total 100 million tons, are distributed over an area of more than $70,000 \mathrm{~km}^{2}$, accounting for $40 \%$ of the total land area. It was reported that as of December 31, 2019, there were 249 coal mines in production in Guizhou Province, with a total production capacity is 133.52 million tons per year. High sulfur (S) content in the main feature of the coal in Guizhou province, which can be in excess of 3\% [11]. Among the sulfide minerals, $\mathrm{FeS}_{2}$ is the most widespread in nature and is regarded as the main cause of AMD [12,13]. Youyu Catchment in Huaxi District, locating in the upstream of Aha reservoir, which is an important water resource for the Guiyang City, has a 60-year history of coal mining. The coal resources in Huaxi District are shallow, with most of the coal seams being exposed to the ground. It has therefore been proven difficult to conduct large-scale open-pit mining, and only underground mining has been established. During mining activities undertaken in the region's small coal mines, coal bunkers, liver dumps, and sewage treatment tanks are usually established close to the main cave. Coal gangue waste piles are typically disordered, and most have not been treated or protected after mine closure; moreover, the management of coal gangue piles is even less effective. In rainy season, waste piles have been washed away by rainwater, potentially toxic elements may continue to migrate via runoff water. In early 2010, the large-scale mining activities with regard to the environmental and economic aspects had been stopped by the local authority and the government. However, Guizhou is one of the most typical areas of karst landform in China, distributing 1710 springs on the ground with an average flow of 121.23 billion $\mathrm{m}^{3} / \mathrm{a}$. Even after abandonment, the continuously produced AMD with the presence the $\mathrm{O}_{2}$, microorganism, and water, the AMD could still pollute the surrounding environment via springs in rainy days. Therefore, the environmental pollution and potentially ecological risks left by the decades of mining activity may last for very long time. There have been several studies focused on Fe-cycling, metals behavior, and remediation technology in the river, sediment, and soils contaminated by AMD $[2,14,15]$. To date, relatively few studies have reported comprehensively for soil properties and pollution level in Youyu Catchment after a long period time of closure. Even after nine years of self-restoration, Youyu Catchment's pollution is still not removed and the situation is unclear, so the aims of this study were to do the following: (1) estimate the soil acidity, soil sulfur, and levels of potentially toxic elements in the soil nine years after mine closure; (2) identify the sources of potentially toxic elements in the soil; and (3) evaluate the eco-risk posed by the distribution of potentially toxic elements in the soil.

\section{Materials and Methods}

\subsection{Soil Sampling}

Youyu Catchment is located in Huaxi District, Guiyang City, which is in the central area of Guizhou Province, China. The catchment has a total population of approximately 14,227 and covers an area of $53.33 \mathrm{~km}^{2}$. The terrain is mostly mountains and hills. The area has a humid plateau monsoon climate, characterized by a lack of severe cold in winter and of extreme heat in summer, and by abundant rainfall and high humidity. The average annual temperature and rainfall are $14.9^{\circ} \mathrm{C}$ and $1178.3 \mathrm{~mm}$, respectively. The altitude ranges between 1090 and $1450 \mathrm{~m}$. Silico-aluminum yellow soil is the main soil type in the study area. Youyu Catchment is characterized by well-developed agricultural activities, 
with the main products cultivated being tea, vegetables, and fruit. The major industries include coking, cement production, and metal foundries [16]. The soil sample collection method used herein was described by Pan et al. [17]. In June 2019, we collected soil samples surrounding eight coal gangues and six AMD effluents. Briefly, the soil samples were divided into four types: (1) soil samples surrounding (within $100 \mathrm{~m}$ ) coal gangues (SCG); (2) samples within $100 \mathrm{~m}$, where AMD emerges from underground (AMD); (3) soil samples from where tributaries merge into the Youyu River (TM); and (4) soil samples from control areas (CK). A $2 \mathrm{~m} \times 2 \mathrm{~m}$ grid spacing was used for soil sampling, and a total of 27 surface $(0-20 \mathrm{~cm})$ soil samples were collected, using the five-point sampling method. At each sampling site, five subsamples were taken from the same area (approximately $4 \mathrm{~m}^{2}$ ) and pooled to form one composite sample. The sampling sites are illustrated in the Figure 1.

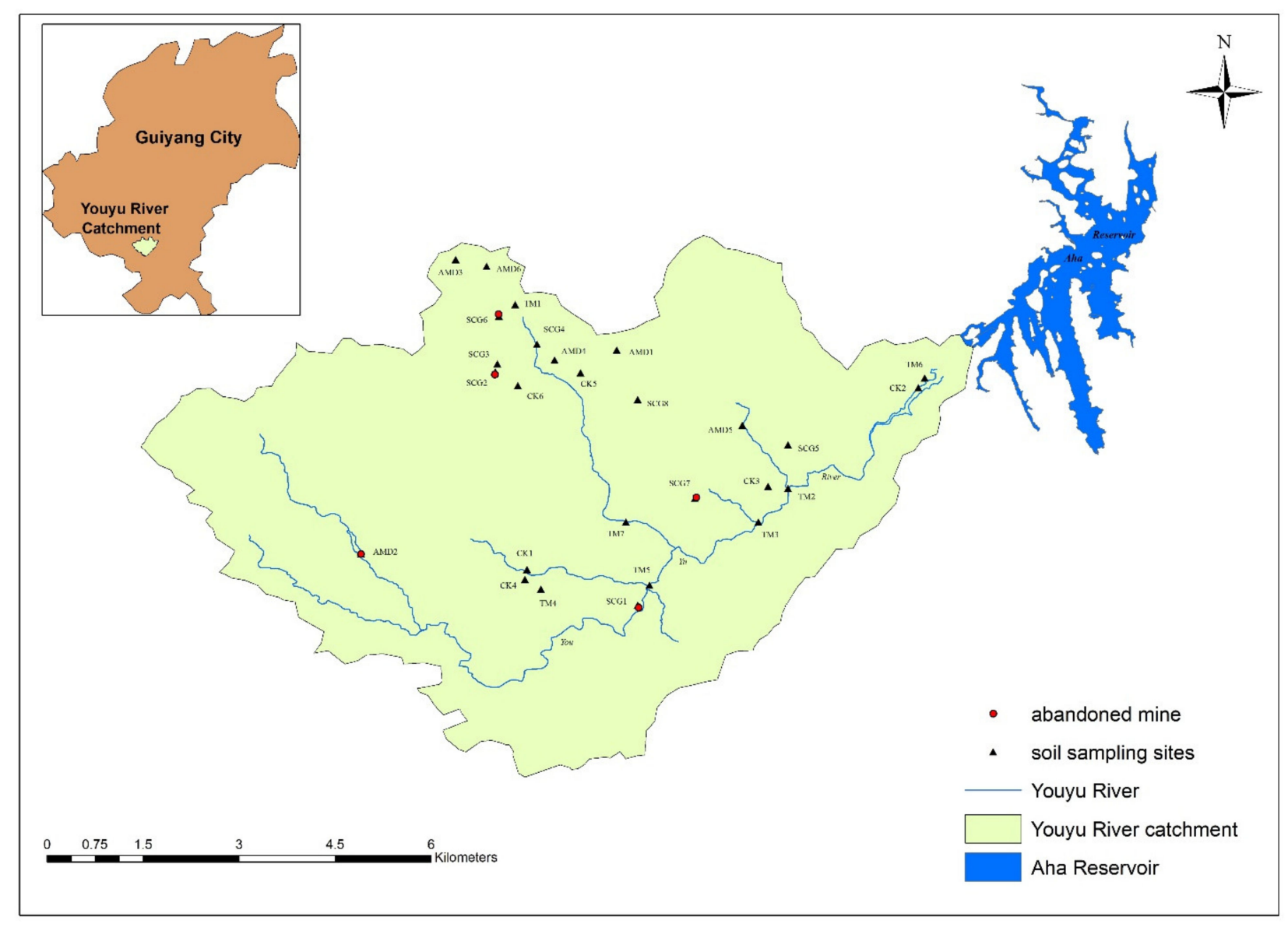

Figure 1. Locations of sampling sites in the studied area.

\subsection{Sample Preparation and Analysis}

All samples were air-dried for 1 week, at room temperature, in a storage room, passed through a 60-mesh sieve after removing stones, residual roots, and other unwanted materials, and then sealed in brown glass bottles and conserved in a refrigerator, at $-4{ }^{\circ} \mathrm{C}$, until analysis. Samples were analyzed by following the 3050B and 6010Cmethods established by the United States Environmental Protection Agency (USEPA) [18,19]. In brief, approximately $10 \mathrm{~g}$ of sample was air-dried, gently ground with an agate mortar, and passed through a 100-mesh nylon sieve. Then, $1 \mathrm{~g}$ of the sample was placed into an Anton PVC (Polyvinyl chloride) digestion vessel together with $9 \mathrm{~mL}$ concentrated nitric acid $\left(\mathrm{HNO}_{3}\right)$ and $3 \mathrm{~mL}$ hydrogen peroxide $\left(\mathrm{H}_{2} \mathrm{O}_{2}\right)$. The vessel was sealed and heated at $180{ }^{\circ} \mathrm{C}$ for $15 \mathrm{~min}$. The concentrations of eight potentially toxic elements (As, $\mathrm{Cd}, \mathrm{Cu}, \mathrm{Pb}, \mathrm{Ni}, \mathrm{Zn}$, $\mathrm{Mn}, \mathrm{Cr}$, and $\mathrm{Hg}$ ) in the digestion solution were determined by using inductively coupled 
plasma-mass spectrometry (ICP-MS; POEMS3; Thermo Fisher Scientific, Waltham, MA, USA).

Iron levels in soil were determined, using the national standard method (HJ 804-2016), with $10.0 \mathrm{~g}$ samples (accurate to $0.01 \mathrm{~g}$ ) placed in a $100 \mathrm{~mL}$ conical flask and $20.0 \mathrm{~mL}$ extract liquid $\left(\mathrm{c} 5(\mathrm{TEA}\right.$, Triethanolamine $)=0.1 \mathrm{~mol} / \mathrm{L}, \mathrm{c}\left(\mathrm{CaCl}_{2}\right)=0.01 \mathrm{~mol} / \mathrm{L}, \mathrm{c}(\mathrm{DTPA}$, Diethylenetriaminepentaacetic acid) $=0.005 \mathrm{~mol} / \mathrm{L}) ; \mathrm{pH}=7.3$ ) then added. The solution was shaken at $20 \pm 2{ }^{\circ} \mathrm{C}$ at a speed of 160 200 r/min for $2 \mathrm{~h}$. The extraction solution was then slowly poured into a centrifuge tube and centrifuged for $10 \mathrm{~min}$. The supernatant was isolated within 48 h of gravity filtration, using a medium-speed quantitative filter paper. Inductively coupled plasma-atomic emission spectrometry was used to detective iron levels.

For measuring $\mathrm{pH}, 10 \mathrm{~g}$ of soil was mixed with $25 \mathrm{~mL}$ of deionized water $(1: 2.5(\mathrm{~m} / \mathrm{v})$ soil-to-water ratio), and the supernatant was measured by using a $\mathrm{pH}$ meter (HQ30d; Hach, Loveland, CO, USA), according to the methods of the People's Republic of China National Environmental Protection Standards (HJ962-2018) [20]. The S content in soil was determined by using an elemental analyzer (PE 2400-II; Perkin Elmer, Waltham, MA, USA).

\subsection{Quality Assurance and Quality Control}

Soil standard reference materials (GBW07401 and GSS-1), obtained from the Center of National Standard Reference Material of China, was used for quality assurance and quality control (QA/QC). The accepted recoveries ranged from $81.0 \%$ to 109\%. Analysis methods were evaluated by using blank $(n=7)$ and duplicate samples $(n=13)$ for each set of samples. The relative deviation of the duplicate samples was $<7 \%$ for all batch treatments.

\subsection{Data Analysis}

The data analysis was performed, using SPSS software (version 18.0; SPSS Inc., Chicago, IL, USA). Descriptive statistics generated for analysis of the potentially toxic elements in the soil samples included the maximum, minimum, median, and mean values, and the standard deviation (SD). Relationships between concentrations of potentially toxic elements were investigated, using Spearman correlation coefficients. The spatial distribution of the concentrations and eco-risks of potentially toxic elements in Huaxi District was visualized, using ArcGIS software (version 10.3; ESRI, Redlands, CA, USA).

\subsection{The Geoaccumulation Index (Igeo)}

The Igeo is a geochemical criterion introduced by Müller [21]. It can be used to evaluate soil contamination by comparing the differences between current and preindustrial concentrations of potential contaminants. Unlike other methods of pollution assessment, the Igeo takes the natural diagenesis process into account, making the assessments more practical. The Igeo was calculated by using the following equation:

$$
\text { Igeo }=\log _{2}\left(C_{n} / 1.5 \times B_{n}\right)
$$

where $C_{n}$ is the measured concentration of the elements in soil $\left(\mathrm{mg} \mathrm{kg}^{-1}\right)$, and $B_{n}$ is the geochemical background value $\left(\mathrm{mg} \mathrm{kg}^{-1}\right)$. A coefficient of 1.5 was applied due to potential variations in the baseline data [22]. The relationships between the Igeo and the pollution levels are given in Supplementary Materials Table S1.

\subsection{Potential Ecological Risk Index (RI)}

The RI, proposed by Hakanson [23], is a relatively rapid, simple, and standard method for assessing the ecological risk posed by potentially toxic elements in soils or sediments [24]. The RI can reflect the potential ecological risk according to the overall pollution level. The formula is as follows:

$$
\mathrm{RI}=\sum E_{r}^{i}=\sum T_{r}^{i}\left(C_{s}^{i} / C_{B}^{i}\right)
$$


The RI is the sum of ecological risk indices of various potentially toxic elements; $E_{r}^{i}$ is the ecological risk factor for individual elements; $C_{S}^{i}(\mathrm{mg} / \mathrm{kg})$ is the concentration of a target element in a sample soil; $C_{B}^{i}(\mathrm{mg} / \mathrm{kg})$ is the background value of the element in Guizhou Province (Table 1); and $T_{r}^{i}$ is the toxicity response factor of each metal. Liu et al. [25] calculated the toxicity response coefficient of $\mathrm{Tl}$ in a potential ecological risk assessment, with the value set to 10 . The toxic response coefficients of $\mathrm{As}, \mathrm{Cd}, \mathrm{Cr}, \mathrm{Cu}, \mathrm{Pb}$, and $\mathrm{Zn}$ were $10,30,2,5,5$, and 1, respectively. The classification standard for the RI of the potentially toxic elements is also shown in Supplementary Materials Table S1.

\section{Results and Discussion}

\section{1. $p H$}

Soil $\mathrm{pH}$ is usually classified into the following five categories: strongly acidic $(\mathrm{pH}<4.5)$, acidic $(4.5 \leq \mathrm{pH}<5.5)$, slightly acidic $(5.5 \leq \mathrm{pH}<6.5)$, neutral $(6.5 \leq \mathrm{pH}<7.5)$, alkaline $(7.0 \leq \mathrm{pH}<8.5)$, and strongly alkaline $(\mathrm{pH} \geq 8.5)[26]$. As shown in Table 1 , the range of soil $\mathrm{pH}$ values in the study area was $0.94-7.77$ (mean, $5.44 \pm 1.46$, i.e., acidic). In contrast to the soil background $\mathrm{pH}$ value (6.2) in Guizhou Province, $60 \%$ of the samples were classified as strongly acidic. The sample site with the most acidic soil conditions was AMD4 (0.94), which was located in an area affected by the largest flows of AMD effluents. Most of the other sites with strongly acidic soil conditions ( $\mathrm{pH}$ range of 3.27-5.89) were located on or surrounding coal gangues, e.g., AMD1, SCG3, and SCG5. In contrast, the soil pH in sites relatively remote from the coal gangues (and thus from the impact of AMD effluents) was neutral to alkaline. Similar trends were also observed in other studies conducted in Youyu Catchment. For example, the $\mathrm{pH}$ was found to be $4.48 \pm 0.93$ in farmland soil from Youyu Catchment, and irrigation by AMD was considered to be the main reason for soil acidification [27]. The farmland and paddy soil $\mathrm{pH}$ values were reported to be $4.52-6.40$ and 4.71-5.55, respectively, in a study conducted in the same area ago, and the soil $\mathrm{pH}$ within $100 \mathrm{~m}$ of coal gangues was lower than that at sites $300 \mathrm{~m}$ away [28]. Studies in other coal-mining areas in Guizhou Province have also revealed a strongly acidic soil pH, e.g., Zhijin mine in Bijie City (4.78-5.38 for paddy soil and 4.995-5.77 for farmland soil), with AMD resulting from high-S ores and gangues identified as the dominant source. The study area was located in the karst landform region of Guizhou Province, which is dominated by carbonate rocks, and the background soil $\mathrm{pH}$ is neutral to slightly alkaline. Since the early 1980s, coal resources have been exploited on a large scale in Youyu Catchment, with numerous small coal mines and several larger private mines forming large-scale goafs. Communication between coal bearing strata and the overlying karst strata has led to karst water flowing into pits and interacting with coal seams, which has generated acidic wastewater containing rusty, yellow-colored granular suspended matter. Because most coal mines are located along the Youyu River, the acid waste water from mining has typically been discharged into the river along the wellhead.

\subsection{Concentrations of Potentially Toxic Elements in Soils}

Descriptive statistics for As, Cd, Cu, Pb, Ni, Zn, Mn, Cr, Hg, Fe, and $\mathrm{S}$ in the 27 soil samples from Youyu Catchment are presented in Table 1 and Figure 2. The background $\mathrm{pH}$ and concentrations of potentially toxic elements in Guizhou Province and the Chinese Environmental Quality Standards for Soils [29] are listed together for reference. Potentially toxic elements were found to be widespread in the study area, with concentration ranges of 4.85-12.94, 0.10-2.85, 4.04-167.92, 5.15-43.11, 3.39-77.73, 10.60-264.58, 6.54-3524.02, 56.37-118.25, 0.006-0.015, 3764.24-185,519.41 mg/kg for As, Cd, Cu, Pb, Ni, Zn, Mn, Cr, $\mathrm{Hg}$, and $\mathrm{Fe}$, and $0.003-2.91 \%$ for $\mathrm{S}$; the respective mean values were $8.74,1.12,62.68,18.40$, $25.95,72.52,593.60,86.06,0.010$, and $35,575.95 \mathrm{mg} / \mathrm{kg}$, and $0.44 \%$. In general, except for $\mathrm{Cd}$, the concentrations of the potentially toxic elements ( $\mathrm{As}, \mathrm{Cu}, \mathrm{Pb}, \mathrm{Ni}, \mathrm{Zn}, \mathrm{Cr}$, and $\mathrm{Hg}$ ) were all below the Chinese environmental quality standards for soils. For $\mathrm{Cd}$, the mean value was $1.12 \mathrm{mg} / \mathrm{kg}$, which was 2.73 times higher than the Chinese standard $(0.30 \mathrm{mg} / \mathrm{kg})$. The As, Cd, Cu, Ni, Zn, Mn, Cr, and Fe concentrations were higher than the soil background 
values in Guizhou Province [30], with the $\mathrm{Cd}, \mathrm{Cu}$, and Fe concentrations being particularly high at $1.12,62.68$, and $35,575.95 \mathrm{mg} / \mathrm{kg}$, which were $1.69,1.95$, and 12.18 times higher than their respective background values. There are no published records of soil background values for $\mathrm{S}$ in Guizhou Province, but when compared to a mountain soil in the adjacent area $(0.11 \%)$ [31], the mean $S$ content in the study area was 3.4 times higher $(0.44 \%)$.

There have been several other studies reporting the levels of potentially toxic elements in the soils of the studied area. According to a study conducted in Youyu Catchment in 2014, the $\mathrm{Cr}, \mathrm{Cu}, \mathrm{Zn}, \mathrm{As}, \mathrm{Cd}$, and $\mathrm{Pb}$ concentrations in the soil surrounding the coal mine were $79.09 \pm 16.48,87.07 \pm 13.28,127.5 \pm 36.23,30.53 \pm 10.82,0.36 \pm 0.15$, and $29.05 \pm 9.04 \mathrm{mg} / \mathrm{kg}$, respectively [27]. In a study in Huaxi District conducted in 2010, the $\mathrm{Hg}$, As, $\mathrm{Cr}, \mathrm{Pb}, \mathrm{Cd}, \mathrm{Fe}$, and $\mathrm{Mn}$ concentrations were $0.15,29.60,62.42,26.56,0.61,31,300$, and $437.52 \mathrm{mg} / \mathrm{kg}$, respectively [32]. Gao et al. [15] determined the total Fe concentration in an abandoned coal mine in Youyu Catchment and reported an AMD volume of $>7000 \mathrm{~m}^{3}$, and a mean Fe concentration of 20,929.65 mg/ kg, which was lower than the value reported in this study. Since 2010, the As, $\mathrm{Hg}$, and Pb concentrations in soils in Youyu Catchment have displayed a downward trend, while the $\mathrm{Cd}, \mathrm{Fe}, \mathrm{Mn}$, and $\mathrm{Cr}$ concentrations have displayed upward trends.

There have been several studies of other high-S coal mines in Guizhou Province [33] determined the $\mathrm{As}, \mathrm{Cd}, \mathrm{Cr}, \mathrm{Cu}, \mathrm{Pb}$, and $\mathrm{Zn}$ concentrations in the soils of Xingren County, which is located in southwest Guizhou where numerous high-S coal mines are located. The As, $\mathrm{Cd}, \mathrm{Cr}, \mathrm{Cu}, \mathrm{Pb}$, and $\mathrm{Zn}$ concentrations were 28.82, 133.75, 1.14, 52.11, 79.63, 44.39, and $118.23 \mathrm{mg} / \mathrm{kg}$, respectively. According to Li [34], at the Zhijin coal mine in western Guizhou Province, the $\mathrm{Hg}$, As, $\mathrm{Cu}, \mathrm{Zn}, \mathrm{Cd}, \mathrm{Pb}, \mathrm{Cr}, \mathrm{Fe}$, and $\mathrm{Mn}$ concentrations in the soil surrounding coal gangues were $0.128,6.94,126.49,85.92,0.56,17.62,157.69,61,689$, and $435.1 \mathrm{mg} / \mathrm{kg}$, respectively. In comparison to these coal-mining areas in Guizhou Province, the concentrations of potentially toxic elements in this study were relatively low. This disparity reflects the variation in potentially toxic element concentrations among different regions in coal-mining areas, as well as the enrichment of potentially toxic elements in soils by anthropogenic activities.

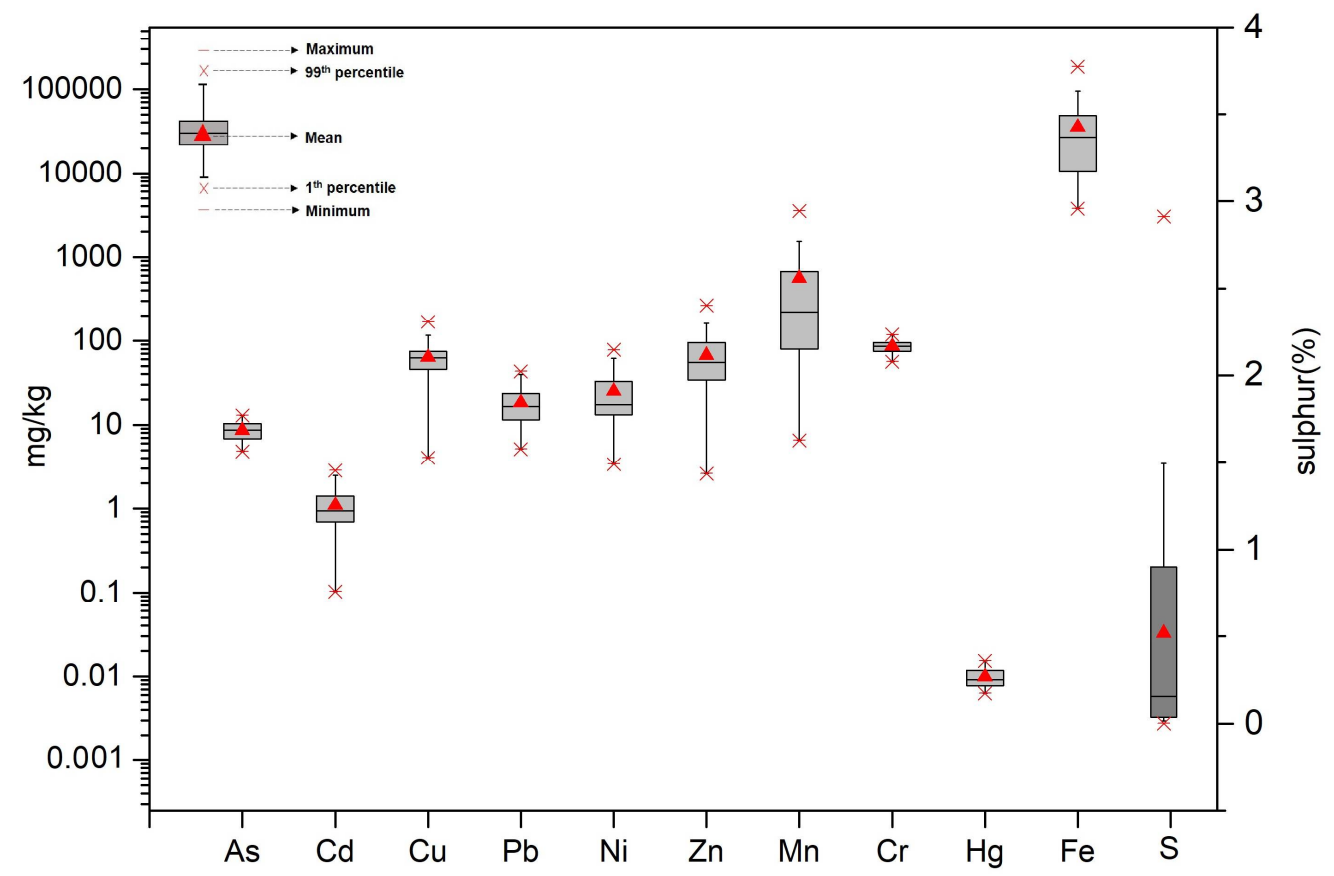

Figure 2. The statistical characteristics (maximum, 99th percentile, median, 1st percentile, and minimum values) of potentially toxic elements in the soil from Youyu Catchment. The concentrations of As, Cd, Cu, Pb, Ni, Zn, Mn, Cr, Hg, Fe refer to the left axis; the percentage of sulfur refers to right axis. 
Table 1. The concentrations, coefficient of variation, and geoaccumulation index (Igeo) values of potentially toxic elements in soils of Youyu Catchment.

\begin{tabular}{|c|c|c|c|c|c|c|c|c|c|c|c|c|}
\hline - & $\mathrm{pH}$ & $\begin{array}{c}\text { As } \\
(\mathrm{mg} / \mathrm{kg})\end{array}$ & $\begin{array}{c}\mathrm{Cd} \\
(\mathrm{mg} / \mathrm{kg})\end{array}$ & $\begin{array}{c}\mathrm{Cu} \\
(\mathrm{mg} / \mathrm{kg})\end{array}$ & $\begin{array}{c}\mathrm{Pb} \\
(\mathrm{mg} / \mathrm{kg})\end{array}$ & $\begin{array}{c}\mathrm{Ni} \\
(\mathrm{mg} / \mathrm{kg})\end{array}$ & $\begin{array}{c}\mathrm{Zn} \\
(\mathrm{mg} / \mathrm{kg})\end{array}$ & $\begin{array}{c}\text { Mn } \\
\text { (mg/kg) }\end{array}$ & $\begin{array}{c}\mathrm{Cr} \\
(\mathrm{mg} / \mathrm{kg})\end{array}$ & $\begin{array}{c}\mathrm{Hg} \\
(\mathrm{mg} / \mathrm{kg})\end{array}$ & $\begin{array}{c}\text { Fe } \\
(\mathrm{mg} / \mathrm{kg})\end{array}$ & $\begin{array}{c}S \\
(\%)\end{array}$ \\
\hline Mean & 5.44 & 8.74 & 1.12 & 62.68 & 18.40 & 25.95 & 72.52 & 593.60 & 86.06 & 0.010 & $35,575.95$ & 0.44 \\
\hline SD & 2.06 & 0.70 & 27.52 & 9.05 & 18.88 & 49.12 & 775.69 & 14.30 & 0.00 & $33,710.01$ & 0.59 & $\mathrm{SD}$ \\
\hline $\mathrm{CV}$ & 23.59 & 62.17 & 43.90 & 49.19 & 72.76 & 72.65 & 130.68 & 16.62 & 24.76 & 94.76 & 132.53 & $\mathrm{CV}$ \\
\hline Igeo & - & -0.13 & 0.22 & -1.26 & -0.79 & -1.05 & -1.51 & -0.11 & -2.65 & 2.47 & - & Igeo \\
\hline CEQS & - & 25.00 & 0.30 & 200.00 & 350.00 & 50.00 & 300.00 & - & 250.00 & 1.00 & - & - \\
\hline $\begin{array}{c}\text { Background } \\
\text { values in } \\
\text { Guizhou } \\
\text { province }\end{array}$ & 6.2 & 8.6 & 0.21 & 32.0 & 26.2 & 23.4 & 67.0 & 482 & 61.0 & 0.040 & 2920 & - \\
\hline
\end{tabular}

CEQS: Chinese Environmental Quality Standards for Soils (CEPA 1995); Background Values in Guizhou Province: CNEMC, 1990.

\subsection{Spatial Distribution of Potentially Toxic Elements}

In general, the sample types were divided into four classes, to represent the abandoned coal area: (1) soil samples surrounding (within $100 \mathrm{~m}$ ) the abandoned coal mines (SCG), (2) samples from where AMD emerges from underground (AMD), (3) soil samples from where tributaries merge into the Youyu River (TM), and (4) soil samples from control areas (CK). As shown in Figures 3 and 4, different soil sample sites displayed varying degrees of pollution. Generally, the soil sampled at TM sites had the highest $\mathrm{Cd}, \mathrm{Cu}, \mathrm{Ni}, \mathrm{Zn}$, and Mn concentrations, while the $\mathrm{As}, \mathrm{Pb}, \mathrm{Cr}$, and $\mathrm{Fe}$ concentrations were highest in the soils at AMD sites; the $\mathrm{Hg}$ concentrations were similar across the five sampling sites. The soil at SGC sites had the highest $S$ content, and conversely had the lowest levels of all potentially toxic elements, except for Fe. Therefore, $\mathrm{Cd}$ and Fe were considered to be the elements of most concern; however, these two elements had different pollution characteristics. The $\mathrm{Cd}$ concentrations followed the order of TM $>$ AMD $>$ SCG > CK, while the Fe concentrations followed the order of AMD $>$ SCG $>$ CK $>$ TM.

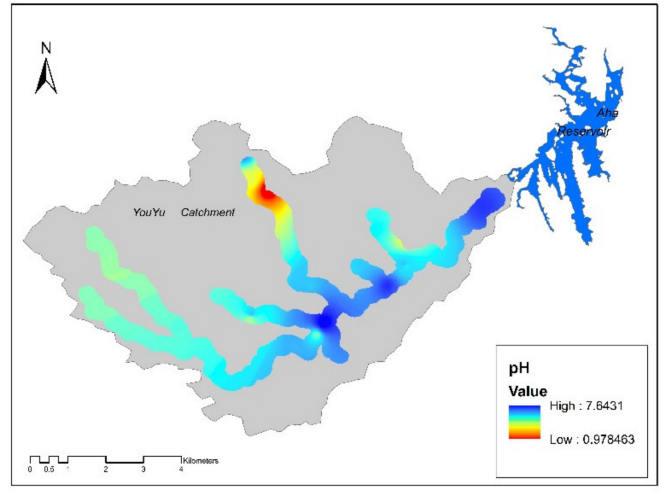

(a)

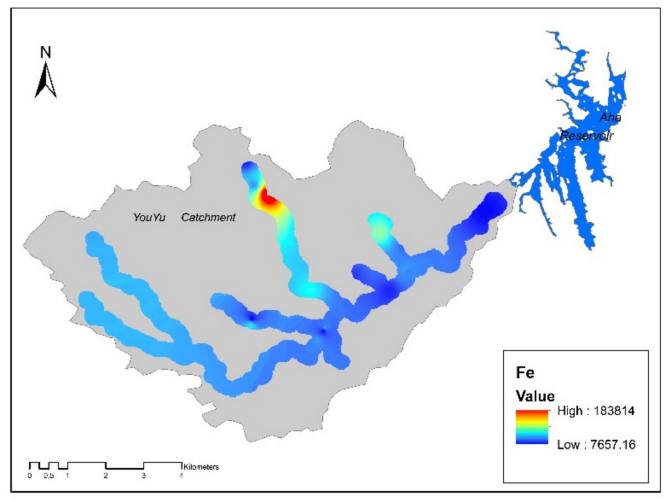

(c)

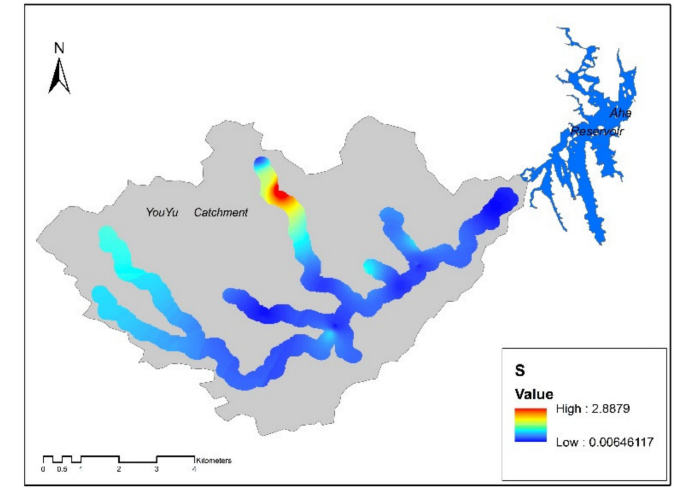

(b)

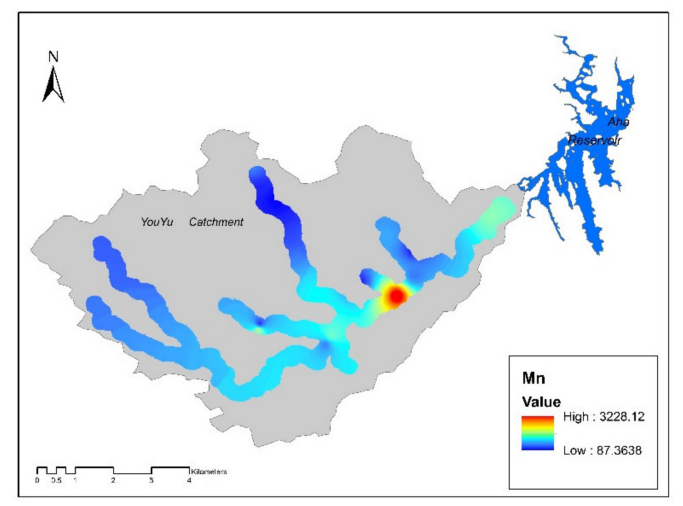

(d)

Figure 3. Cont. 


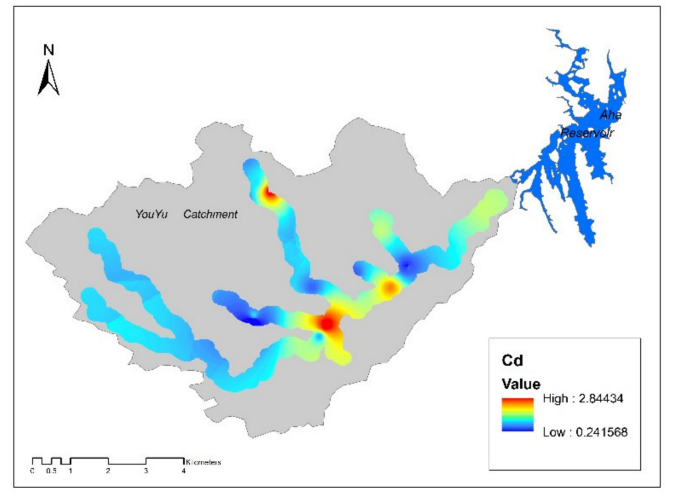

(e)

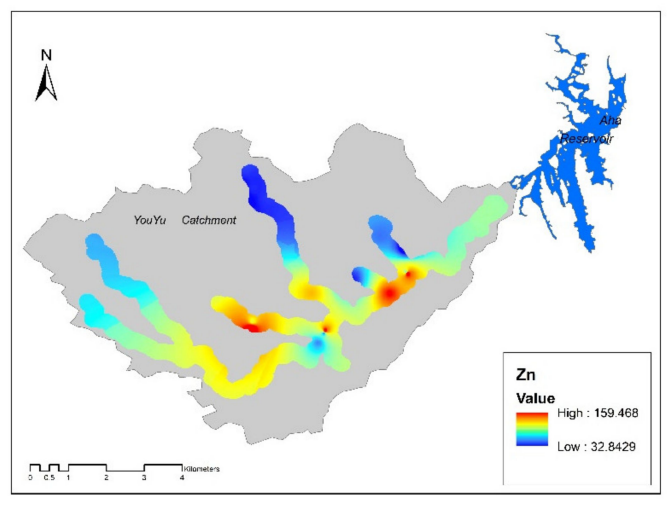

(g)

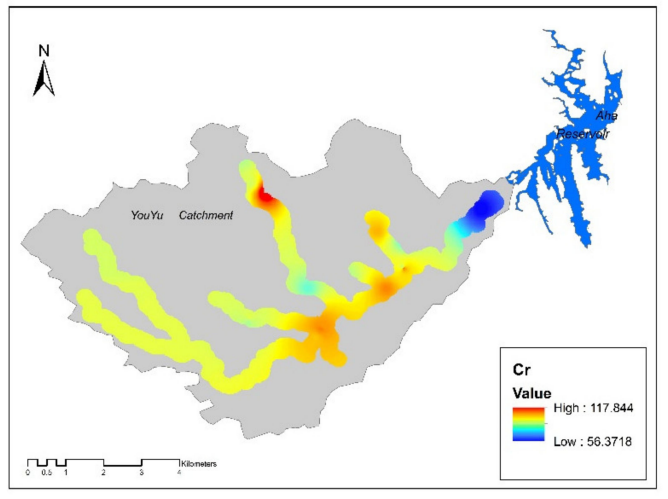

(i)

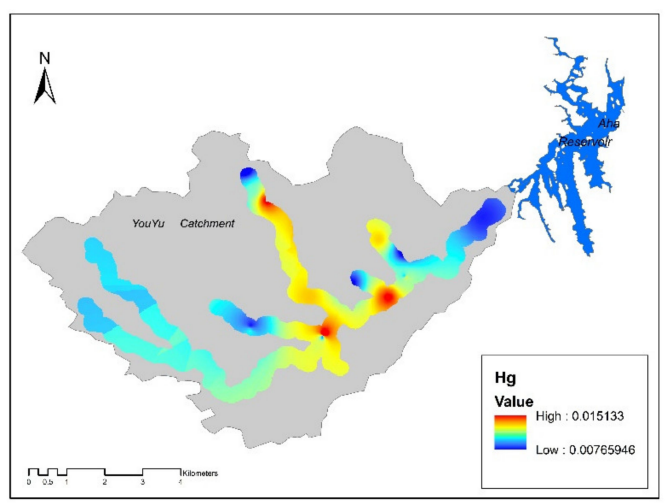

(k)

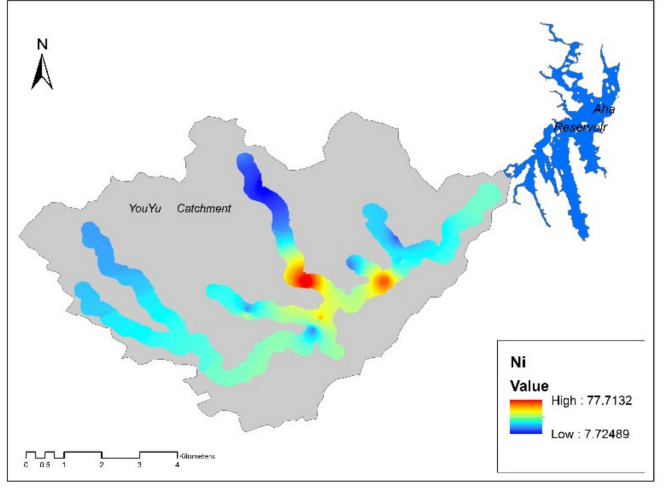

(f)

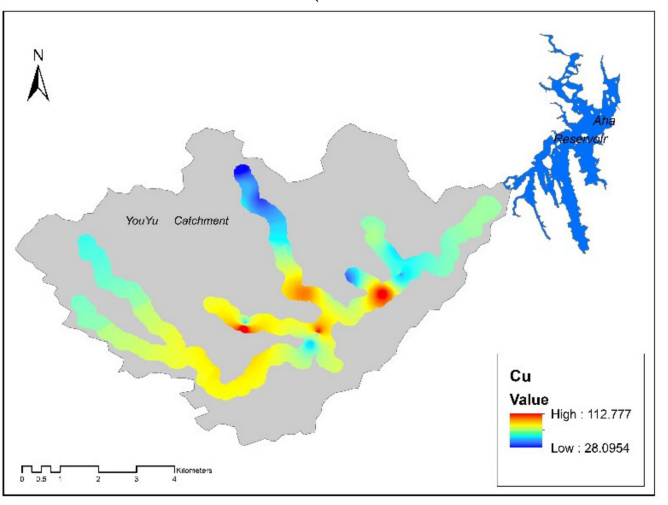

(h)

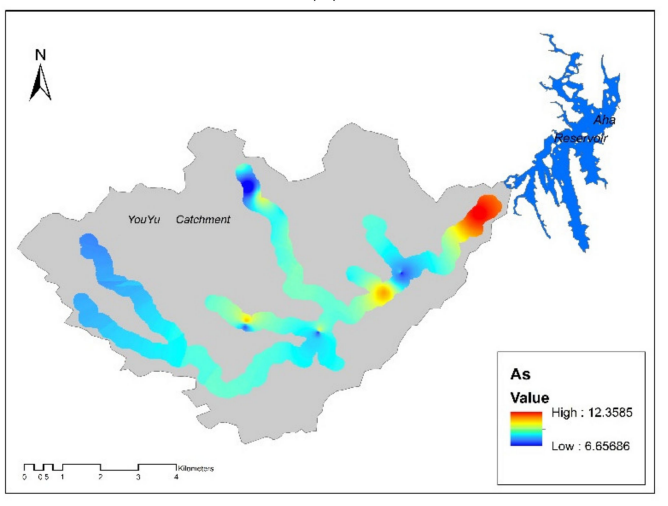

(j)

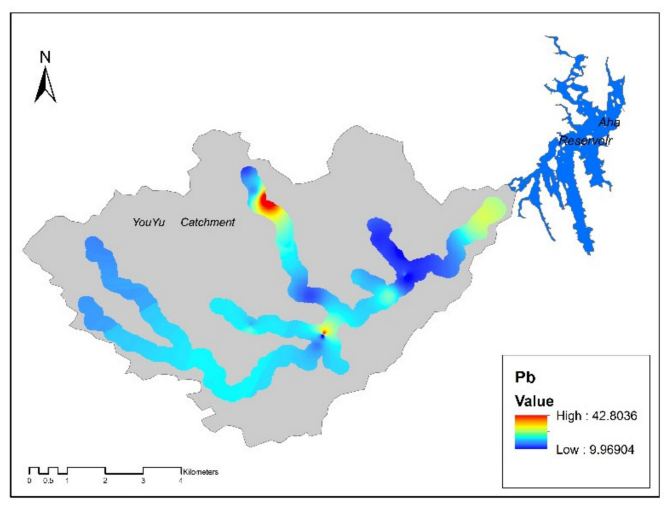

(1)

Figure 3. Spatial distribution of the concentrations of potential toxic elements inYouyu catchment. (a) $\mathrm{pH}$ value; (b) $\mathrm{S}$ value; (c) Fe value; (d) Mn value; (e) Cd value; (f) Ni value; (g) Zn value; (h) Cu value; (i) Cr value; (j) As value; (k) Hg value; (l) $\mathrm{Pb}$ value. 


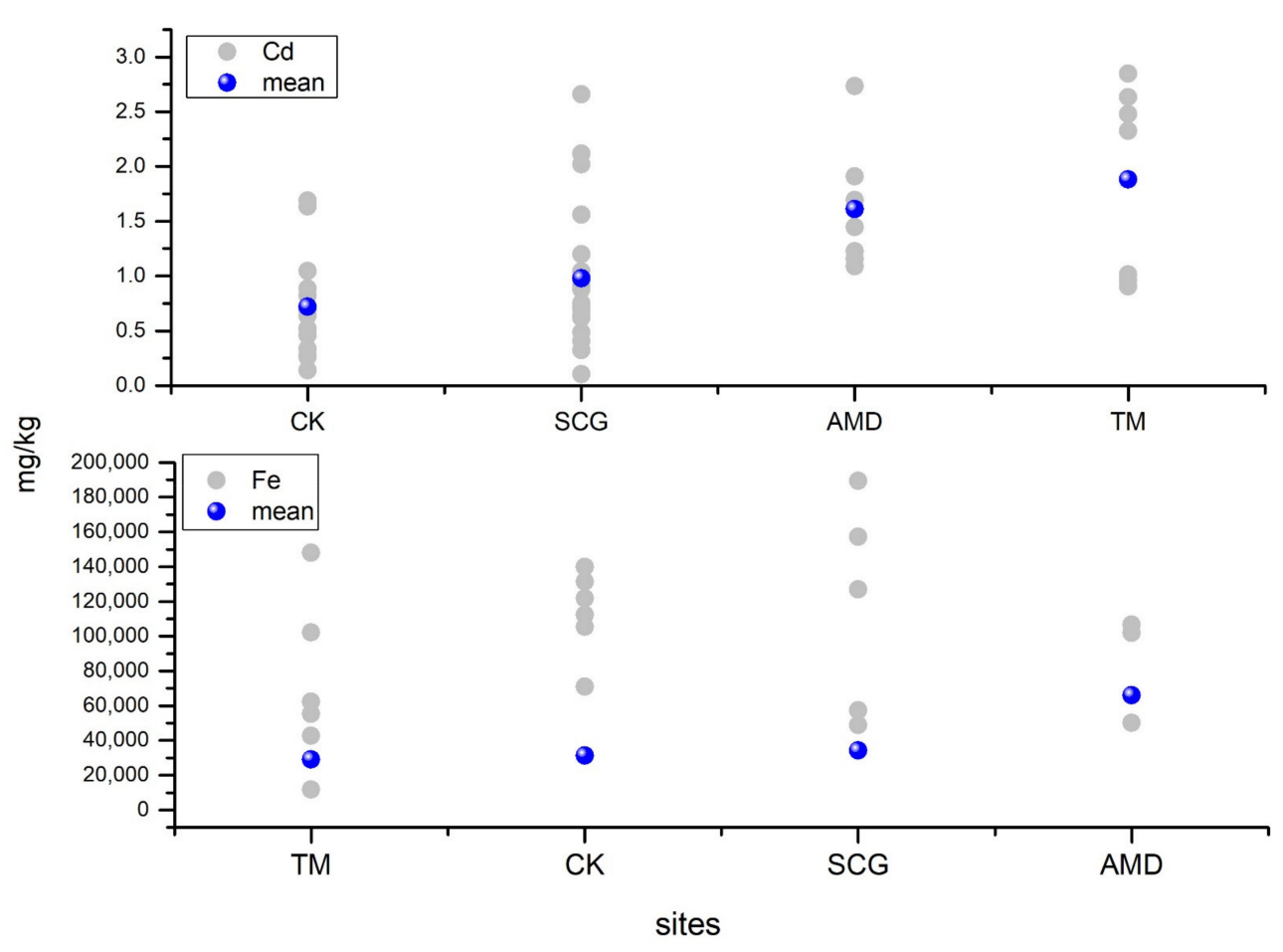

Figure 4. The concentrations of $\mathrm{Cd}$ and Fe in the soil from different sites in Youyu Catchment.

\subsection{Ecological Risk of Potentially Toxic Elements}

The method of Hakanson [23] was adopted to assess the ecological risk posed by heavy metal pollution in the topsoil of the study area. Hakanson developed a quantitative approach that has been used in many other studies, to assess the ecological risk posed by heavy metals in soil $[35,36]$. Supplementary Materials Table S2 shows the potential ecological risk values, $\mathrm{E}(\mathrm{i})$, of eight potentially toxic elements in the topsoil in Youyu Catchment. The mean $\mathrm{E}(\mathrm{i})$ values of $\mathrm{As}, \mathrm{Cr}, \mathrm{Cu}, \mathrm{Ni}, \mathrm{Pb}, \mathrm{Zn}$, and $\mathrm{Hg}$ were all less than 40, indicating that these metals posed a low ecological risk. Cadmium had a higher mean $\mathrm{E}(\mathrm{i})$ value (51.16) than the other seven heavy metals, thus presenting a moderate potential ecological risk. Overall, $61.8 \%$ of all samples had an $\mathrm{E}(\mathrm{Cd})$ value in the range of 40 to 80 , while $14.5 \%$ were in the range of 80 to 160 , representing moderate and considerable potential ecological risk, respectively. The RIs were calculated to assess the risk of multiple potential toxic elements in soils. The RI values for $91.0 \%$ of all samples were $<160$, indicating a low potential ecological risk, while the other $9.0 \%$ of samples posed a moderate ecological risk. As shown in Figures 5 and 6, the spatial distribution of $\mathrm{E}(\mathrm{Cd})$ is consistent with that of $\mathrm{RI}$, indicating that the potentially ecological risks in the studied area was dominated by $\mathrm{Cd}$.

The oxidation of sulfides releases $\mathrm{H}^{+}, \mathrm{Fe}^{2+}$, and $\mathrm{SO}_{4}{ }^{2+}$, which is the first step in the environmental accumulation of potentially toxic elements in the environment. However, the subsequent migration of elements is also controlled by a series of complex precipitation, hydrolysis, adsorption and desorption, co-precipitation, and ion exchange reactions. In general, the highest concentrations of $\mathrm{Fe}, \mathrm{S}$ and the lowest $\mathrm{pH}$ values were all observed in the AMD sites. At the AMD sites, soil Fe and $\mathrm{S}$ concentrations had significant negative correlations with soil $\mathrm{pH}(\mathrm{P}>0.01, \mathrm{Fe}: \mathrm{R}=-0.83, \mathrm{~S}: \mathrm{R}=-0.93)$, suggesting that the Fe and $\mathrm{S}$ concentrations were higher at lower $\mathrm{pH}$ values. This was the karst landscape facilitated AMD outflows, resulting in massive amounts of $\mathrm{Fe}^{3+}, \mathrm{H}^{+}$, and $\mathrm{SO}_{4}{ }^{2-}$ being leached into the soil, thus causing significantly high $\mathrm{Fe}$ and $\mathrm{S}$ concentrations and extremely low $\mathrm{pH}$ values in the soil at AMD sites. It was also apparent that the Fe concentration displayed a decreasing trend with distance from AMD and SCG sites, while $\mathrm{pH}$ displayed the opposite trend. 


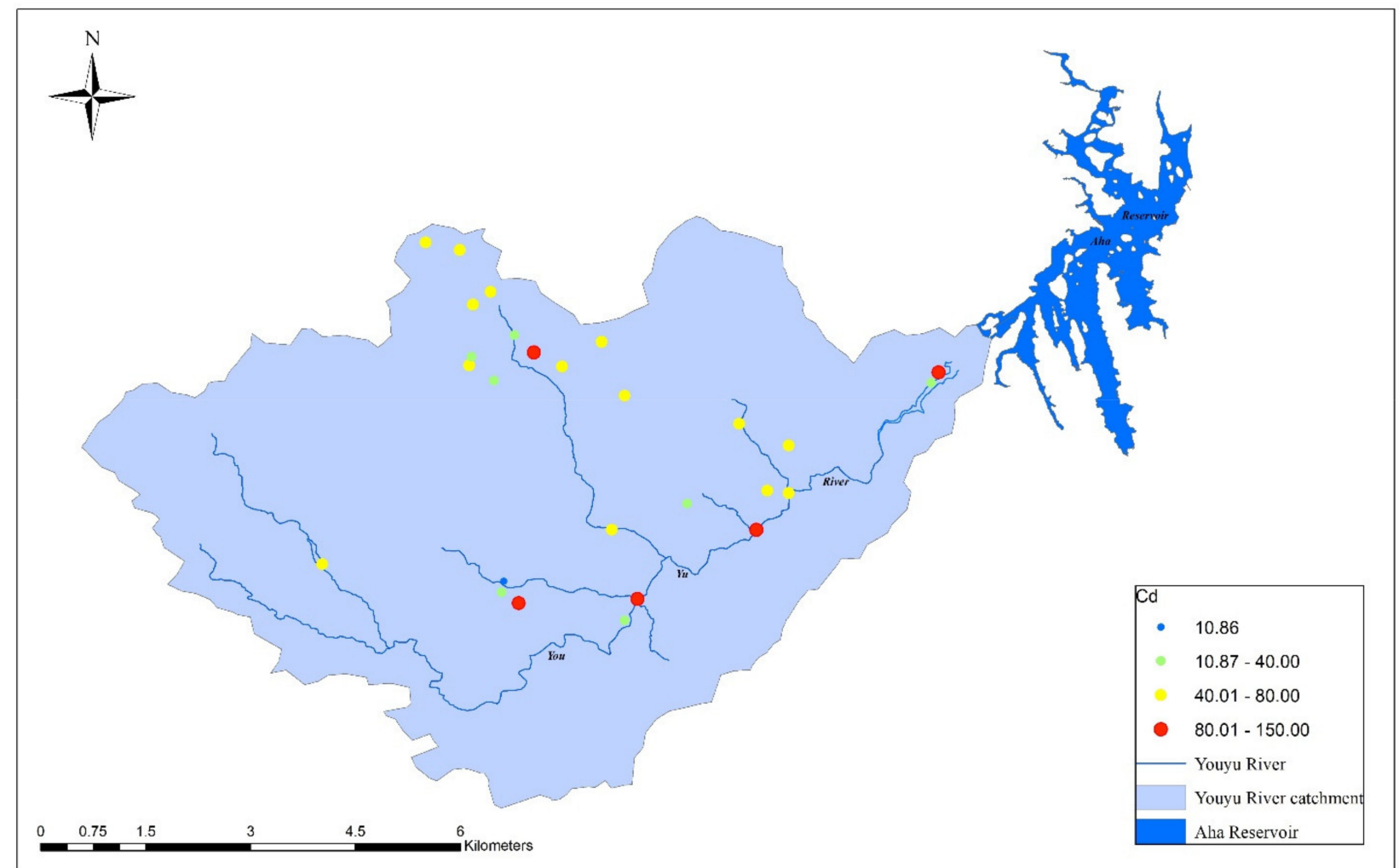

Figure 5. Spatial distribution of the potential ecological risks (E(i)) for $\mathrm{Cd}$ in the soil of the studied area.

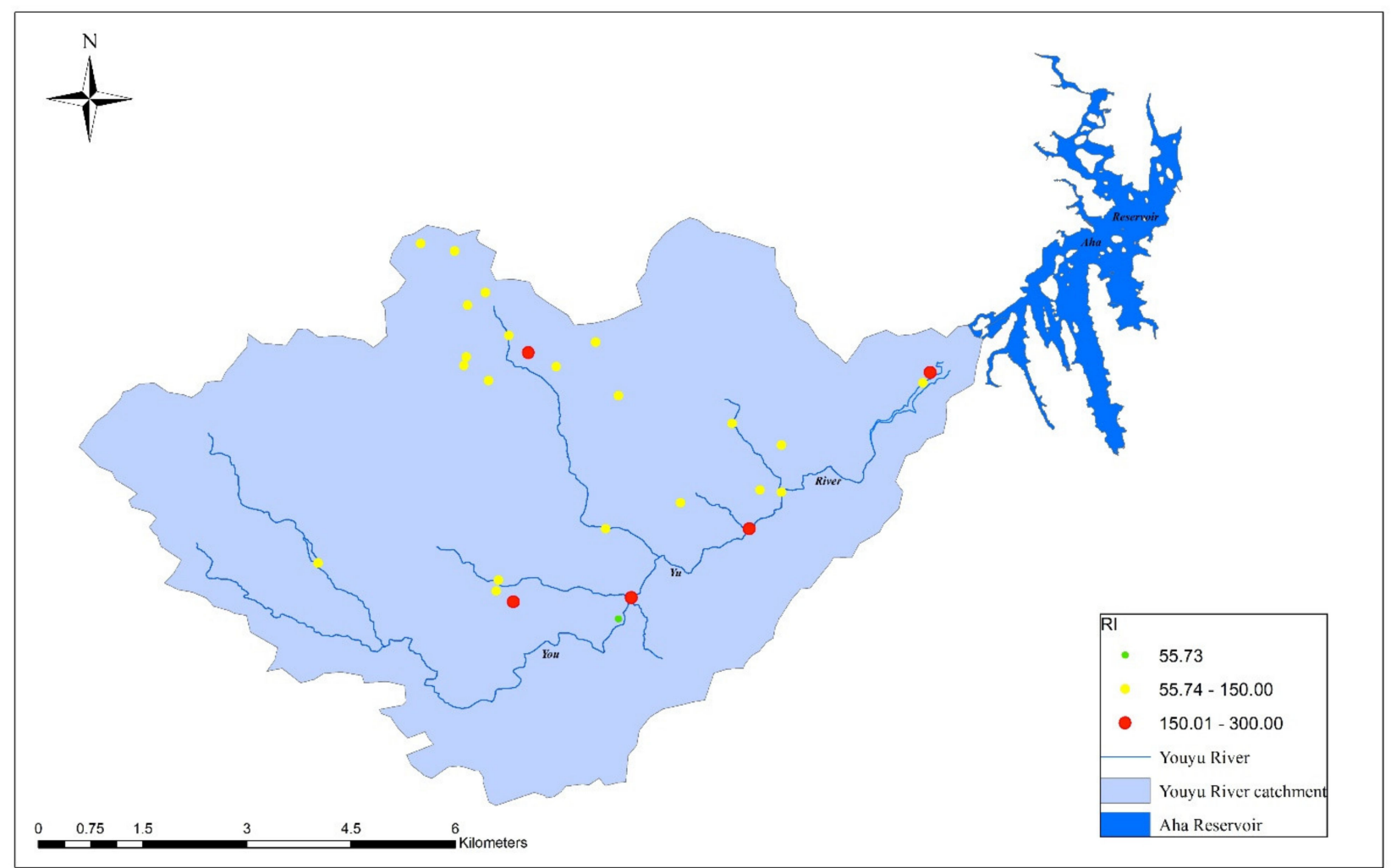

Figure 6. Spatial distribution of the potential ecological risk indices (RIs) in the soil of the studied area. 
However, compared to $\mathrm{Fe}$, the $\mathrm{Cd}$ concentrations displayed the opposite trend, being highest in the TM sites and thus implying other pollution sources. Based on the field investigation, coal mining at the AMD sites and abandoned coal mines was responsible for the direct introduction of $\mathrm{Cd}$ into the surface environment. However, there were also numerous exposed coal seams upstream of TM sites. The local karst area was dominated by a lithologic soil that has been substantially affected by the carbonate rocks. The soil was shallow and neutral to slightly alkaline due to the lack of a transition layer, and the affinity and adhesion between the underlying rock and soil was poor. For a long period of time, the local area has had a tropical and subtropical climate, and has therefore experienced humid and hot conditions with high precipitation, resulting in strong chemical leaching activities. Leaching or weathering of these residues may transfer $\mathrm{Cd}$ and other elements downhill to the TM soils, which can then migrate onto farmland and into surface waters. It has been reported that soil $\mathrm{Cd}$ is more likely to migrate under acidic conditions $(\mathrm{pH}<6)[14,37]$, but is more likely to deposit as $\mathrm{Cd}(\mathrm{OH})_{2}$ or other precipitates in an alkaline environment $(\mathrm{pH}>6)$. In contrast, Fe is more inclined to precipitate under acidic conditions [38], which was the case in this study. In the TM sites, the Cd concentration showed a significantly negative correlation $(p<0.01, \mathrm{R}=0.97)$ with $\mathrm{pH}$ (mean value, 6.76), while in the SCG and AMD sites, which had the highest soil Fe concentrations, there was a significant positive correlation $(p<0.01, \mathrm{R}=0.96)$ between the Fe concentration and $\mathrm{pH}$ (mean value, 4.35). The above results indicated that with distance from AMD and SCG sites, the $\mathrm{pH}$ tended to be higher and soil $\mathrm{Cd}$ tended to precipitate, while Fe tended to precipitate under a low soil $\mathrm{pH}$. However, it should be recognized that the migration of various elements in the mining area varied with the chemical properties of solid minerals and solutions. There are likely to be multiple migration mechanisms, which should be studied further in combination with an analysis of the various chemical forms of soil elements. The TM sites showed higher $\mathrm{Cd}$ concentrations compared to other sites in the upper reach; as mentioned above, $\mathrm{Cd}$ is more likely migrate under acid condition and absorbed into sediment under opposite condition. Yuan et al. [39] reported that, under flood conditions, sediments are easily mixed with water, and potentially toxic elements-rich sediments are enriched in the soil around the river and in the lower-lying terrain. It can be seen that river sediments are not only the enrichment area of potentially toxic elements but also the secondary pollution sources with potential hazards to water quality and the surrounding soil. In addition, coal wastes are often used by local residents to increase the height of riverbanks, and can also be enriched in river sediment. Under flood conditions, the sediments will mix with river water, and the soil around the river and surrounding low-lying terrain can become enriched with sediment [39]. Runoff from tributaries of the Youyu River has decreased annually, especially in the dry season, and the bare riverbed has formed a soil over a long period. The levels of $\mathrm{Cd}$ and other potentially toxic elements in soil may also be influenced by agricultural activities, such as irrigation with contaminated water and fertilization. In addition, due to the prohibition of mining activities, tea plantations have been established by local famers in recent years. Phosphate fertilizer is used by local farmers, to improve soil fertility, and has had an important influence on soil quality.

After 2010, the mines in this area were successively closed, and the pits were all sealed. However, AMD formation became more extensive after mine closure, because the pumps used to keep the water table near open-pit and/or underground mines artificially low, to facilitate mining activities, were turned off. This has resulted in a rise in the groundwater level, which then comes into contact with the exposed sulfide minerals on wall rocks, causing AMD to be continuously generated. In addition, even if all the pits were sealed, groundwater would flow in the form of karst gaps, pores, karst caves, pipes, and underground rivers, due to the karst landforms. Rock cutting and fragmentation create favorable conditions for groundwater storage, migration, and dissolution. Surface water and groundwater are exchanged frequently, and karstification is strong. Water usually emerges from the ground in the form of springs, seriously contaminating the surrounding aquatic and soil environment. At the same time, coal gangues from the coal mines have 
been randomly deposited in the area, and harmful components are leached out by rainfall leaching, which then pollutes surface water, groundwater, and soil. According to the spatial distribution of potentially ecological risk posed by Cd (Figure 5 and Table 2), the sites where tributaries merged with the main steam of the river had the highest pollution levels. Soil pollutants can enter rivers through leaching, where they may harm aquatic organisms in the wet season, and further endanger human health via the food chain.

Table 2. The potential ecological risks of potentially toxic elements in soils from different sites of Youyu Catchment.

\begin{tabular}{|c|c|c|c|c|c|c|c|c|c|}
\hline Sampling Sites & As & $\mathrm{Cd}$ & $\mathrm{Cu}$ & $\mathrm{Pb}$ & $\mathbf{N i}$ & $\mathrm{Zn}$ & $\mathrm{Cr}$ & $\mathrm{Hg}$ & RI \\
\hline $\mathrm{TM}$ & 10.39 & 85.60 & 11.66 & 3.87 & 10.71 & 1.66 & 3.08 & 14.50 & 141.47 \\
\hline AMD & 11.27 & 73.17 & 8.93 & 3.61 & 5.11 & 0.91 & 3.26 & 12.30 & 118.56 \\
\hline SCG & 9.63 & 44.78 & 8.95 & 3.11 & 3.69 & 0.69 & 2.75 & 9.45 & 83.06 \\
\hline CK & 10.78 & 32.84 & 11.29 & 3.62 & 5.96 & 1.35 & 2.66 & 9.00 & 77.50 \\
\hline Mean & 10.17 & 51.16 & 9.79 & 3.51 & 5.55 & 1.01 & 2.82 & 9.87 & 93.87 \\
\hline Median & 10.46 & 43.84 & 9.82 & 3.14 & 3.91 & 0.82 & 2.82 & 9.12 & 82.15 \\
\hline Maximum & 15.04 & 129.70 & 26.24 & 8.23 & 16.61 & 3.95 & 3.88 & 15.24 & 199.51 \\
\hline Minimum & 5.64 & 4.69 & 0.63 & 0.98 & 0.72 & 0.04 & 1.85 & 6.32 & 38.96 \\
\hline SD & 2.40 & 31.81 & 4.30 & 1.73 & 4.04 & 0.73 & 0.47 & 2.44 & 36.25 \\
\hline
\end{tabular}

TM: Youyu River; AMD: acid mine drainage; SCG: surrounding (within $100 \mathrm{~m}$ ) coal gangues; CK: control areas.

Cadmium is considered to be one of the most toxic trace elements in the environment, and can cause serious health problems in animals and humans [40]. Cadmium accumulation in grains and vegetables has received much attention [41]. Cadmium pollution of the edible parts of grains and vegetables is particularly serious in China, due to rapid industrialization and the wide application of agrochemicals in agricultural activities. It has been reported that $\mathrm{Cd}$ is the main element responsible for soil heavy-metal contamination in China, and poses the highest potential ecological risk in both rural and urban areas. The highest soil Cd concentrations have been reported in south China, e.g., the YunnanGuizhou Plateau. However, there are many other hotspots in China, due to mining and smelting activities, with the soil in mining and smelting areas having much higher $\mathrm{Cd}$ concentrations than in areas where other land uses predominate, such as irrigation, urban, and remote areas [42-44].

\section{Conclusions}

Obvious acidification and enrichment of potentially toxic elements was observed in the soils of Youyu Catchment, especially Cd, S, and Fe. Among all elements in the study area, the highest concentrations were observed for $\mathrm{Cd}$ and $\mathrm{Fe}$, with $\mathrm{Cd}$ and Fe being present at unpolluted to moderately polluted and heavily polluted levels, respectively. Significantly high Fe and S concentrations and extremely low $\mathrm{pH}$ values were found in the soils of AMD sites, and the sites where tributaries merged with the TM had the highest Cd concentrations. Iron contamination originated mainly from the non-point sources of AMD and coal gangues, while the adsorption and desorption of AMD and agricultural activity resulted in high $\mathrm{Cd}$ levels in the estuary. Cadmium levels posed a moderate ecological risk, while the other elements, such as $\mathrm{As}, \mathrm{Cr}, \mathrm{Pb}, \mathrm{Zn}, \mathrm{Cu}, \mathrm{Ni}$, and $\mathrm{Hg}$, all posed a low eco-risk. Spatially, the TM sites had the highest Cd eco-risk; moreover, they tended to pose a significant risk of harm to aquatic ecosystems, particularly in the wet season, and endangered human health via the food chain.

Supplementary Materials: The following are available online at https:/ / www.mdpi.com/2075-163 $\mathrm{X} / 11 / 3 / 330 / \mathrm{s} 1$, Table S1: Contamination categories on the basis of Igeo values and ecological risk indices; Table S2: Potentially ecological risks values of the elements of $\mathrm{As}, \mathrm{Cd}, \mathrm{Cu}, \mathrm{Pb}, \mathrm{Ni}, \mathrm{Zn}, \mathrm{Cr}$, and $\mathrm{Hg}$.

Author Contributions: Conceptualization, L.P. and X.G.; methodology, L.P.; software, L.P. and B.L.; validation, L.P. and Y.C.; formal analysis, L.P.; investigation, X.G., B.L., Y.C., Z.H., J.P., Y.P., Y.Z.; resources, L.P.; data curation, L.P.; writing—original draft preparation, L.P. and B.L.; writing—review 
and editing, L.P.; visualization, L.P.; supervision, X.G. and L.P.; project administration, Chinese Research Academy of Environmental Sciences; funding acquisition, X.G. All authors have read and agreed to the published version of the manuscript.

Funding: This study was supported by the National Key R\&D Plan (2018YFC1801302) and Chinese Research Academy of Environmental Sciences, State Key Laboratory of Environmental Criteria and Risk Assessment (201520 and 201542).

Institutional Review Board Statement: Not applicable.

Informed Consent Statement: Not applicable.

Data Availability Statement: Not applicable.

Acknowledgments: We would like to thank all those who helped with the sampling.

Conflicts of Interest: The authors declare no conflict of interest.

\section{References}

1. Simate, G.S.; Ndlovu, S. Acid mine drainage: Challenges and opportunities. J. Environ. Chem. Eng. 2014, 2, 1785-1803. [CrossRef]

2. Park, I.; Tabelin, C.B.; Jeon, S.; Li, C.L.; Seno, K.; Ito, M.; Hiroyoshi, N. A review of recent strategies for acid mine drainage prevention and mine tailings recycling. Chemosphere 2019, 219, 588-606. [CrossRef]

3. Gray, N. Environmental impact and remediation of acid mine drainage: A management problem. Environ. Geol. 1997, 30, 62-71. [CrossRef]

4. Manzano, M.; Ayora, C.; Domenech, C.; Navarrete, P.; Antonio, G.; Maria-Jesús, T. The impact of the Aznalcóllar mine tailing spill on groundwater. Sci. Total Environ. 1999, 242, 189-209. [CrossRef]

5. Wates, J.A.; Rykaart, E.M. The Performance of Natural Soil Covers in Rehabilitating Opencast Mines and Waste Dumps in South Africa; Research Report 575/1/99; Water Research Commission: Pretoria, South Africa, 1999.

6. Hua, C.H.; Zhou, G.Z.; Yin, X.; Wang, C.Z.; Chi, B.R.; Cao, Y.Y.; Wang, Y.; Zheng, Y.; Cheng, Z.R.; Li, R.Y. Assessment of heavy metal in coal gangue: Distribution, leaching characteristic and potential ecological risk. Environ. Sci. Pollut. Res. 2018, 25, 32321-32331. [CrossRef] [PubMed]

7. Druschel, G.K.; Baker, B.J.; Gihring, T.M.; Banfield, J.F. Acid mine drainage biogeochemistry at iron mountain, California. Geochem. Trans. 2004, 5, 13-32. [CrossRef]

8. Azhari, A.E.; Rhoujjati, A.; Hachimi, M.L.E.; Ambrosi, J. Pollution and ecological risk assessment of heavy metals in the soil-plant system and the sediment-water column around a former $\mathrm{Pb} / \mathrm{Zn}$-mining area in NE Morocco. Ecotoxicol. Environ. Saf. 2017, 144, 464-474. [CrossRef]

9. Hallberg, K.B. New perspectives in acid mine drainage microbiology. Hydrometallurgy 2010, 104, 448-453. [CrossRef]

10. Johnson, D.B.; Hallberg, K.B. Acid mine drainage remediation options: A review. Sci. Total Environ. 2005, 338, 3-14. [CrossRef]

11. Department of Natural Resource of Guizhou Province. 2019. Available online: http://zrzy.guizhou.gov.cn/zfxxgk/zfxxgkml/ tjsj_81192/gtzyddjcjb/201907/t20190702_25808845.html (accessed on 2 June 2019).

12. Evangelou, V.P. Pyrite Oxidation and its Control; CRC Press: Boca Raton, FL, USA, 1995.

13. Tabelin, C.B.; Igarashi, T.; Villacorte-Tabelin, M.; Park, I.; Opiso, E.M.; Ito, M.; Hiroyoshi, N. Arsenic, selenium, boron, lead, cadmium, copper, and zinc in naturally contaminated rocks: A review of their sources, modes of enrichment, mechanisms of release, and mitigation strategies. Sci. Total Environ. 2018, 645, 1522-1553. [CrossRef] [PubMed]

14. Equeenuddin, S.M.; Tripathy, S.; Sahoo, P.K.; Panigrahi, M.K. Metal behavior in sediment associated with acid mine drainage stream: Role of pH. J. Geochem. Explor. 2013, 124, 230-237. [CrossRef]

15. Gao, P.; Sun, X.X.; Xiao, E.Z.; Xu, Z.X.; Li, B.Q.; Sun, W.M. Characterization of iron-metabolizing communities in soils contaminated by acid mine drainage from an abandonded coal mine in Southwest China. Environ. Sci. Pollut. Res. 2019, 26, 9585-9598. [CrossRef] [PubMed]

16. Huaxi Annals Compilation Committee. Huaxi Annuals; Guizhou People's Publishing House: Bejing, China, 2007. (In Chinese)

17. Pan, L.B.; Ma, J.; Wang, X.L.; Hou, H. Heavy metals in soils from a typical county in Shanxi Province, China: Levels, sources and spatial distribution. Chemosphere 2016, 148, 248-254. [CrossRef]

18. USEPA. Method 3050B: Acid Digestion of Sediments, Sludges and Soils; United States Environmental Protection Agency: Washington, WA, USA, 1996.

19. USEPA. Method 6010C: Inductively Coupled Plasma Atomic Emission Spectrometry; United States Environmental Protection Agency: Washington, WA, USA, 1996.

20. CEPA (Chinese Environmental Protection Administration). Soil-Determination of pH-Potentiometry (HJ962-2018). In National Environmental Protection Standards of the People's Republic of China; China Environmental Science Press: Beijing, China, 2018. (In Chinese)

21. Müller, G. Index of geoaccumulation in sediments of the Rhine River. Geojournal 1969, 2, 108-118.

22. Solgi, E.; Esmailisari, A.; Riyahibakhtiari, A.; Hadipour, M. Soil contamination of metals in the three industrial estates, Arak, Iran. Bull. Environ. Contam. Toxicol. 2012, 88, 634-638. [CrossRef] 
23. Hakanson, L. An ecological risk index for aquatic pollution control, a sedimentological approach. Water Res. 1980, 14, 975-1001. [CrossRef]

24. $\mathrm{Wu}, \mathrm{Q} . ; \mathrm{Qi}, \mathrm{J} . ; \mathrm{Xia}, \mathrm{X}$. Long-term variations in sediment heavy metals of a reservoir with changing trophic states: Implications for the impact of climate change. Sci. Total Environ. 2017, 609, 242-250. [CrossRef]

25. Liu, J.; Luo, X.W.; Wang, J.; Xiao, T.F.; Chen, D.Y.; Sheng, G.D.; Yin, M.L.; Lppold, H.; Wang, C.L.; Chen, Y.H. Thallium contamination in arable soils and vegetables around a steel plant-A newly-found significant source of tl pollution in South China. Environ. Pollut. 2017, 224, 445-453. [CrossRef] [PubMed]

26. Institute of Soil Science; Chinese Academy of Sciences. Chinese Soil; Scientific Publisher: Beijing, China, 1978.

27. Zhu, H.L.; Liu, H.Y.; Long, J.H.; Yan, Z.Y. Pollution characteristics of heavy metals in soils in typical polluted areas of Guizhou Province. Earth Environ. 2014, 4, 505-512. (In Chinese)

28. Yang, L.J.; Long, J.; Li, J.; Wu, D.; Liu, F.; Liao, H.K.; Han, S. Effect of Acidic Waste Water from Coal Mine on Cu Form Change in Coal Gangue and Surrounding Farmland Soils. Guizhou Agri. Sci. 2011, 9, 88-91.

29. CEPA (Chinese Environmental Protection Administration). Environmental Quality Standard for Soils (GB 15618-1995); China Environmental Science Press: Beijing, China, 1995. (In Chinese)

30. CNEMC (China National Environmental Monitoring Center). Soil Elements Background Values in China; China Environmental Science Press: Beijing, China, 1990. (In Chinese)

31. Yang, C.; Liu, C.Q.; Song, Z.L.; Liu, Z.M.; Zheng, H.Y. Distribution characteristics of carbon, nitrogen and sulphur of plants and soils in Guizhou karst mountain area, southwestern China. J. Beijing For. Univ. 2008, 30, 45-51. (In Chinese)

32. Li, J. Investigation and Study on Heavy Metal Pollution in Abandoned Coal Mine and Surrounding Soil in Huaxi District of Guiyang; Guizhou University: Guizhou, China, 2010. (In Chinese)

33. Jiang, F.; Ren, B.Z.; Andrew, H.; Deng, R.J.; Wang, Z.H. Distribution, source indentification, and ecological-health risks of potentially toxic elements (PTEs) in soil of Thallium mine area (southwest Guizhou, China). Environ. Sci. Pollut. Res 2019, 26, 16556-16567. [CrossRef]

34. Li, J. Study on Pollution Characters and Migration Rules of Heavy Metals on High-Sulfur Coal Gangue Abandoned Land; China University of Mining and Technology: Beijing, China, 2012. (In Chinese)

35. Sun, Y.; Zhou, Q.; Xie, X.; Liu, R. Spatial, sources and risk assessment of heavy metal contamination of urban soils in typical regions of Shenyang, China. J Hazard Mater 2010, 174, 455-462. [CrossRef] [PubMed]

36. Wang, H.; Lu, S. Spatial distribution, source identification and affecting factors of heavy metals contamination in urban-suburban soils of Lishui City, China. Environ. Earth Sci. 2011, 64, 1921-1929. [CrossRef]

37. Yang, W.J.; Ding, K.B.; Zhang, P.; Qiu, H.; Cloquet, C.; Wen, H.J.; Morel, J.L.; Qiu, R.L.; Tang, Y.T. Cadmum stable isotope variation in a mountain are impacted by acid mine drainage. Sci. Total Environ. 2019, 646, 696-703. [CrossRef]

38. Cathes, L.M. Attempts to model the industrial-scale leaching of copper-bearing mine waste in environmental geochemistry of sufide oxidation. Ame Chem. Soc. 1994, 550, 123-131.

39. Yuan, H.; Song, S.; An, S.; Liu, E. Ecological risk assessment of potentially toxic elements (PTEs) in the soil-plant system after reclamation of dredged sediment. Environ. Sci. Pollut. Res. 2018, 25, 29181-29191. [CrossRef]

40. Wang, M.; Chen, W.P.; Peng, C. Risk assessment of Cd polluted paddy soils in the industrial and township areas in Hunan, Southern China. Chemosphere 2016, 144, 346-351. [CrossRef]

41. Kosolsaksakul, P.; Farmer, J.G.; Oliver, I.W.; Graham, M.C. Geochemical associations and availability of cadmium (Cd) in a paddy field system, northwestern Thailand. Environ. Pollut. 2014, 187, 153-161. [CrossRef] [PubMed]

42. Chen, H.Y.; Teng, Y.G.; Lu, S.J.; Wang, Y.Y.; Wang, J.S. Contamination features and health risk of soil heavy metals in China. Sci. Total Environ. 2015, 512, 143-153. [CrossRef]

43. Zhang, X.Y.; Chen, D.M.; Zhong, T.Y.; Zhang, X.M.; Cheng, M.; Li, X.H. Assessment of cadmium(Cd) concentration in arable soil in China. Environ. Sci. Pollut. Res. 2015, 22, 4932-4941. [CrossRef] [PubMed]

44. Qi, G.X.; Jia, Y.F.; Liu, W.J.; Wei, Y.H.; Du, B.; Fang, W.; Guo, Y.M.; Guo, F.; Wu, Y.H.; Zou, Q.; et al. Leaching behavior and potential ecological risk of heavy metals in Southwestern China soils applied with sewage sludge compost under acid precipitation based on lysimeter trials. Chemosphere 2020, 249, 126212. [CrossRef] [PubMed] 